\title{
Chronic exertional compartment syndrome in the differential diagnosis of peripheral artery disease in older patients with exercise-induced lower limb pain
}

Citation for published version (APA):

de Bruijn, J. A., Wijns, K. C. A., van Kuijk, S. M. J., Hoogeveen, A. R., Teijink, J. A. W., \& Scheltinga, M. R. M. (2021). Chronic exertional compartment syndrome in the differential diagnosis of peripheral artery disease in older patients with exercise-induced lower limb pain. Journal of Vascular Surgery, 73(6), 21142121. https://doi.org/10.1016/j.jvs.2020.11.027

Document status and date:

Published: 01/06/2021

DOI:

10.1016/j.jvs.2020.11.027

Document Version:

Publisher's PDF, also known as Version of record

Document license:

Taverne

Please check the document version of this publication:

- A submitted manuscript is the version of the article upon submission and before peer-review. There can be important differences between the submitted version and the official published version of record.

People interested in the research are advised to contact the author for the final version of the publication, or visit the DOI to the publisher's website.

- The final author version and the galley proof are versions of the publication after peer review.

- The final published version features the final layout of the paper including the volume, issue and page numbers.

Link to publication

\footnotetext{
General rights rights.

- You may freely distribute the URL identifying the publication in the public portal. please follow below link for the End User Agreement:

www.umlib.nl/taverne-license

Take down policy

If you believe that this document breaches copyright please contact us at:

repository@maastrichtuniversity.nl

providing details and we will investigate your claim.
}

Copyright and moral rights for the publications made accessible in the public portal are retained by the authors and/or other copyright owners and it is a condition of accessing publications that users recognise and abide by the legal requirements associated with these

- Users may download and print one copy of any publication from the public portal for the purpose of private study or research.

- You may not further distribute the material or use it for any profit-making activity or commercial gain

If the publication is distributed under the terms of Article $25 \mathrm{fa}$ of the Dutch Copyright Act, indicated by the "Taverne" license above, 


\title{
Chronic exertional compartment syndrome in the differential diagnosis of peripheral artery disease in older patients with exercise-induced lower limb pain
}

\author{
Johan A. de Bruijn, MD, PhD, ${ }^{a}$ Kim C. A. Wijns, MSc, ${ }^{a}$ Sander M. J. van Kuijk, PhD, ${ }^{b}$ \\ Adwin R. Hoogeveen, MD, PhD, ${ }^{c}$ Joep A. W. Teijink, MD, PhD, d,e and Marc R. M. Scheltinga, MD, PhD, ${ }^{a}$ \\ Veldhoven, Maastricht, and Eindhoven, The Netherlands
}

\begin{abstract}
Objective: Peripheral artery disease (PAD) and chronic exertional compartment syndrome (CECS) both cause exerciseinduced lower limb pain. CECS is mostly described in young individuals and may therefore not be considered in older patients with intermittent claudication. The aim of our study was to identify differences in characteristics and symptomatology between patients with CECS and PAD that may help in recognizing CECS in patients $\geq 50$ years with exercise-induced lower limb pain.
\end{abstract}

Methods: In this case-control study, patients with CECS $\geq 50$ years were selected from a prospectively followed cohort and compared with a sample of newly diagnosed patients with PAD $\geq 50$ years. A questionnaire assessed frequency and severity of lower limb pain, tightness, cramps, muscle weakness, and altered skin sensation at rest and during exercise.

Results: At rest, patients with CECS ( $n=43,42 \%$ female, 57 years; range, 50-76 years) reported significantly more pain, tightness, muscle weakness and altered skin sensation (all $P<.01$ ) than patients with PAD ( $n=41,39 \%$ female, 72 years; range, 51-93 years). Having CECS was associated with a significantly higher combined symptom score at rest $(P=.02)$. During exercise, patients with CECS experienced more tightness, muscle weakness and altered sensation $(P<.01)$, but not pain and cramps $(P=.36 ; P=.70)$. Exercise-induced complaints occurred much later in patients with CECS than in patients with PAD (15 minutes vs 4 minutes; $P<.01$ ). Persistence of pain over 4.5 minutes proved most discriminative for the presence of CECS (sensitivity, 95\%; specificity, 54\%; positive predictive value, 65\%). Exercise cessation completely alleviated complaints in all patients with PAD $(n=41)$ but not in $73 \%(n=29)$ of the patients with CECS. Ongoing discomfort strongly predicted the presence of CECS (sensitivity, 73\%; specificity, 100\%; positive predictive value, 100\%).

Conclusions: Patients with CECS $\geq 50$ years report a symptom pattern that is different from patients with PAD. These differences may aid vascular surgeons in identifying older patients with CECS. (J Vasc Surg 2021;73:2114-21.)

Keywords: Intermittent claudication; Peripheral artery disease; Chronic exertional compartment syndrome; Older patients

The differential diagnosis of exercise-induced lower limb pain is primarily determined by age. In older patients, pain and discomfort following mild exertion are often referred to as intermittent claudication (IC). If orthopedic or neurologic disorders are excluded, IC is mostly caused by lower extremity peripheral artery

From the Department of Surgery, Máxima Medical Center, Veldhoven ${ }^{a}$; the Department of Clinical Epidemiology and Medical Technology Assessment, MUMC+, Maastricht ${ }^{\mathrm{b}}$; the Department of Sports Medicine, Máxima Medical Center, Veldhoven ; the Department of Surgery, Catharina Hospital, Eindhoven $^{\mathrm{d}}$; and the Department of Epidemiology, Caphri Research School, Maas tricht University, Maastricht. ${ }^{\mathrm{e}}$

Author conflict of interest: none.

Correspondence: Johan de Bruijn, MD, Department of Surgery, Máxima Medical Center, de Run 4600, PO Box 7777, 5504 DB Veldhoven, The Netherlands (e-mail: cecs.resurge@mmc.nl).

The editors and reviewers of this article have no relevant financial relationships to disclose per the JVS policy that requires reviewers to decline review of any manuscript for which they may have a conflict of interest.

0741-5214

Copyright $\odot 2020$ by the Society for Vascular Surgery. Published by Elsevier Inc https://doi.org/10.1016/j.jvs.2020.11.027 disease (PAD). PAD is quite rare in patients younger than 50 years, but its prevalence increases to $14.5 \%$ in individuals over 70 years of age. ${ }^{2}$

In individuals younger than 50 years, however, exercise-induced lower limb pain is rarely owing to PAD. In these individuals, a variety of other vascular (popliteal artery entrapment syndrome, iliac endofibrosis, polycystic adventitial disease) and nonvascular entities (medial tibial stress syndrome [MTSS], nerve entrapments) may cause $\mathrm{IC}^{3-7}$ In roughly one in seven young individuals, exercise-induced lower limb pain is caused by a chronic exertional compartment syndrome (CECS). ${ }^{8}$ In patients with CECS, pain arises shortly after initiation of exercise and decreases again after cessation. ${ }^{9,10}$ Additional complaints such as tightness, cramps, muscle weakness, or altered leg/ foot skin sensation are also reported. ${ }^{11}$ Findings during physical examination are usually not sensitive, although distal arterial pulsations are normal. ${ }^{12}$

Although both PAD and CECS are associated with exercise-induced pain, patients with PAD are usually 
older and often report risk factors such as smoking, hypercholesterolemia and inactivity. ${ }^{13}$ Conversely, CECS is described mostly in young and active individuals, particularly athletes and military personnel.14,15 Reports describing CECS in older nonathletic individuals and diabetics are scarce. ${ }^{16,17}$ Owing to these contrasting patient populations, CECS may be overlooked as a cause of exercise-induced lower limb pain in older patients.

Our hospital serves as a national referral center for exercise-induced lower limb pain and is exposed to large volumes of individuals with CECS. Our vascular surgeons actively participate in the management of these patients with CECS. As a consequence, CECS is regularly diagnosed in older patients who were previously suspected of having lower extremity PAD. In addition, we found that older CECS patient often have less specific characteristics than their younger counterparts. ${ }^{18}$ The present study aimed to compare these older patients with CECS with patients with PAD. By identifying similarities and differences in patient characteristics and symptoms, we hope to improve recognition of CECS in older patients and aid vascular surgeons in determining which patients require consultation of a sports physician.

\section{METHODS}

Maxima Medical Center in Veldhoven and Eindhoven, the Netherlands, provides general care in a mixed rural and urban area in the southeastern part of the Netherlands. The department of sport medicine serves as a tertiary referral center for exercise-induced syndromes. ${ }^{4,19}$ As such, a wide variety of patients with conditions such as CECS, MTSS, nerve entrapments, and iliac endofibrosis both from within and outside our catchment area are evaluated at an outpatient clinic. Our research group has a special focus on CECS and includes sports physicians and (vascular) surgeons.

Patient selection. The current study compares two patient groups. The first is composed of patients aged $\geq 50$ years who were diagnosed with CECS between January 2013 and March 2018. Starting in January 2013, each patient who was evaluated for CECS was asked to complete a standardized questionnaire. For the current study, only individuals aged $\geq 50$ years who completed this questionnaire were selected. Individuals who at the time of evaluation had pathology potentially interfering with the clinical picture (PAD, venous insufficiency, neurologic conditions, or significant previous lower limb trauma or surgery) were excluded.

The second sample is composed of patients with IC who were diagnosed with PAD between November 2017 and December 2018. A single nurse practitioner performed the initial intake and inclusion, but all patients were also evaluated by an experienced vascular surgeon. Patients with advanced PAD (rest pain and wounds) were evaluated elsewhere. Patients were eligible if they

\section{ARTICLE HIGHLIGHTS}

Type of Research: Single-center, prospective casecontrol study

- Key Findings: At rest, patients with chronic exertional compartment syndrome (CECS) $\geq 50$ years of age $(n=43)$ experienced significantly more symptoms than patients with peripheral artery disease $(P A D) \geq 50$ years of age $(n=41)$. Complaints arose slower in the CECS group than in the PAD group (15 vs 4 minutes; $P<.01$ ). Exercise-cessation alleviated complaints in all 41 patients with PAD, but not in 73\% of the patients with CECS.

- Take Home Message: Differences between both groups may help clinicians in recognizing CECS and may allow for earlier referral to a sports physician for appropriate diagnostics.

had lower limb PAD and completed the same questionnaire as mentioned elsewhere in this article. Individuals were excluded when complaints also included the upper leg or gluteal muscle, if they were unable to complete the questionnaire, if they had interfering lower limb comorbidity (such as orthopedic or neurologic disorders), if the time between the questionnaire and vascular testing was $>4$ months, if they were $<50$ years, or if additional tests were inconclusive. All consecutively evaluated patients with PAD who fulfilled the inclusion criteria and were willing to participate were asked for the study until group size approximated the number of patients with CECS.

Diagnostic steps in both patient groups. Patients suspected of having CECS were assessed by two experienced sports physicians. History and symptoms were evaluated and a physical examination was aimed at finding signs traditionally associated with CECS, such as a tender muscle compartment upon palpation. Chronic arterial and venous insufficiency was ruled out by carefully examining both legs, including an inspection of nail and foot perfusion, palpation of the distal arteries, and an assessment of edema or visible superficial venous convolutes. We screened for popliteal entrapment and/ or neurologic pathology by palpating the distal arteries, a pedal pulse test, and a brief neurologic examination. An ankle brachial systolic pressure index (ABI) or vascular imaging were only performed when there were signs of vascular disorders.

When the history and physical examination were suggestive of CECS, a dynamic intracompartmental pressure measurement (ICP) was performed in all potentially affected compartments of the (most symptomatic) leg using a previously described slit catheter technique. ${ }^{20}$ We refrained from routinely measuring all leg compartments to minimize morbidity. For this test, symptoms 
were provoked with a standardized treadmill test during which patients were instructed to walk or run until the characteristic symptoms emerged. If this provocation was inconclusive or insufficient, they were instructed to hop, walk on their toes, climb stairs, or walk on their heels until painful sensations occurred. We considered intramuscular pressure pathologically elevated if it exceeded one or more of the following cut-off points of $\geq 15 \mathrm{~mm} \mathrm{Hg}$ at rest, $\geq 30 \mathrm{~mm} \mathrm{Hg} 1$ minute after provocation, or $\geq 20 \mathrm{~mm} \mathrm{Hg} 5$ minutes after provocation. ${ }^{21}$ Patients were diagnosed with a lower limb CECS when their history and physical examination were suggestive and intramuscular pressure surpassed one or more of the cut-off points.

Patients with IC complaints potentially having PAD underwent physical examination aimed at finding primary signs (decreased femoral artery, popliteal artery, posterior tibial artery, and/or dorsal pedal artery pulsations) or secondary signs of arterial insufficiency (skin and nail abnormalities). The attending surgeon also actively screened for potential comorbidities, such as orthopedic disorders, neurologic disorders, CECS, or MTSS during the physical examination. When the history and physical examination were consistent with a diagnosis of $P A D$, an $A B I$ was performed during a standardized treadmill test. $A$ rest $A B I$ of $<0.90$ or a decrease of more than $15 \mathrm{~mm} \mathrm{Hg}$ after walking were required for the diagnosis $P A D$. If the $A B I$ was inconclusive, ultrasound examination, magnetic resonance angiography (MRA), or computed tomography angiography were performed to detect peripheral arterial stenoses. Patients were diagnosed with PAD when the history and physical examination were consistent with arterial insufficiency and $A B I$ (or ultrasound examination, MRA, or computed tomography angiography) confirmed the diagnosis. None of the patients with PAD was suspected for CECS based on a suggestive history and physical examination. ICP measurements were, therefore, not performed to rule out CECS in these patients with PAD because they are invasive and only support a mostly clinical diagnosis.

Questionnaire. All patients included in the current study completed a similar questionnaire. It was initially designed to quantify symptoms associated with CECS and was routinely handed over to all patients who were evaluated for CECS at the department of sports medicine since January 2013. Pain, tightness, cramps, muscle weakness, and altered sensation are rated at rest and during exercise on a 5-point verbal rating scale in terms of intensity (no, mild, moderate, severe, or extremely severe) and frequency (never, sometimes, half of the time, most of the time, or always). The intensity (score 0-4) and frequency (score 0-4) of each symptom were combined in a symptom score (Intensity $\times$ Frequency; range, 0-16). In addition, we calculated a combined symptom score as a measure of total complaint burden at rest and during exercise (pain score + tightness score + cramp score + muscle weakness score + altered sensation score; range, 0-80). In the questionnaire, patients were also asked to estimate the time from the initiation of exercise until onset of complaints, and whether and how long symptoms continued after cessation of the provocative activity. Furthermore, all patients were asked which leg(s) were affected and how many months they experienced complaints before the diagnosis. An identical questionnaire was presented to patients with exercise-induced complaints owing to PAD. The questionnaire was unaltered save the omission of several CECS-specific questions. PAD-specific signs were assessed during the physical examination.

Statistical methods and ethical aspects. All analyses were performed with IBM SPSS statistics, version 22.0.0.0. Data are expressed as mean ( \pm standard deviation and range) when normally distributed, or as median (with range) if skewed. Potential differences in patient characteristics were assessed with a chi square test (nominal variables) or a $t$-test (continuous variables). The time from the initiation of the provocative activity until the onset of complaints and symptom scores were compared using a Mann-Whitney $U$ test. We used the receiver operating characteristic curve to determine the most discriminative (highest sensitivity and specificity) time from the initiation of the activity to the onset of complaints. Once determined, the positive predictive value (PPV) of the diagnosis of CECS was calculated. Differences regarding the continuation of complaints after cessation of the provocative activity were assessed with a Fisher's exact test. The PPV of persistent complaints after cessation of the provocative activity for the diagnosis of CECS was also calculated. Associations between either CECS or PAD and the value of the combined symptom score at rest and during exercise were assessed using multivariate linear regression analyses. Before conducting these analyses, we identified gender, age, duration of complaints, and bilaterality as potential confounders and corrected for these variables.

All procedures performed in this study are in accordance with the ethical standards of our institutional research committee and with the declaration of Helsinki. The local medical ethical committee judged that the rules laid down in the Medical Research Involving Human Subjects Act did not apply to the study protocol.

\section{RESULTS}

Between January 2013 and March 2018, we evaluated 1011 patients suspected of CECS at our department of sports medicine. Of the 754 patients who completed a questionnaire, 375 were diagnosed with CECS (Fig 1). A total of 45 (12\%) were $\geq 50$ years. Because some items on the questionnaire were missing in two patients, 43 patients with CECS were included in the current study. 


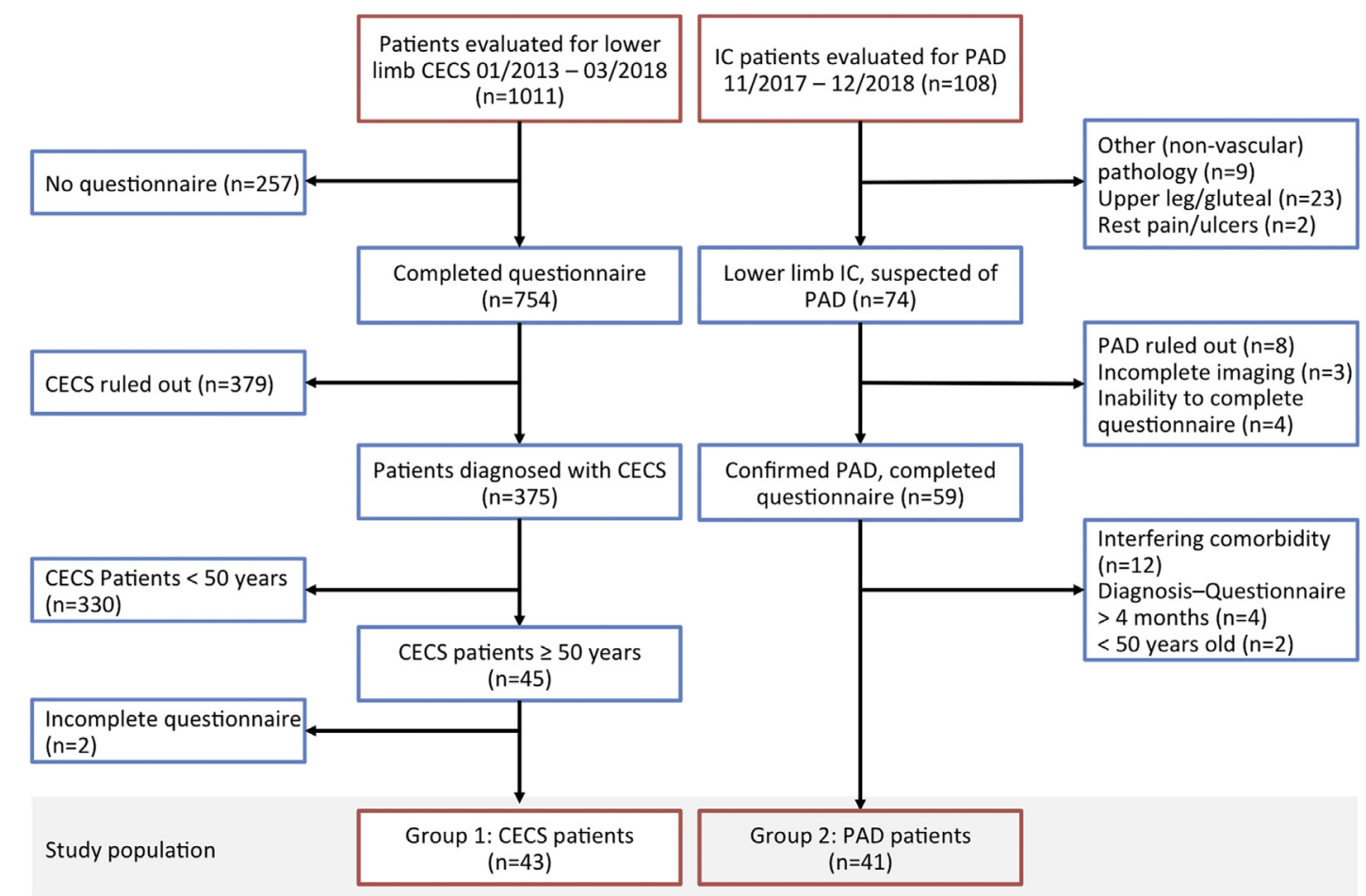

Fig 1. Patient selection. Chronic exertional compartment syndrome (CECS), intermittent claudication (IC), and peripheral artery disease $(P A D)$. Interfering comorbidities were neurologic $(n=9)$, polymyalgia rheumatica $(n=2)$, or gonartrosis $(n=1)$.

During a 14 month-period, 108 consecutive patients were evaluated for potential PAD by the nurse practitioner under the guidance of the vascular surgeon. Lower limb PAD was confirmed in 63 patients, of whom 59 completed the questionnaire. Because 18 patients were excluded owing to interfering lower limb comorbidities ( $n=12$ ), a prolonged period ( $>4$ months) between the completion of the questionnaire and the diagnosis (as confirmed by the $A B \mid$ or vascular imaging; $n=4$ ), or age $<50$ years $(n=2)$, the PAD group consists of 41 patients. The mean rest $A B I$ of the most symptomatic leg was $0.62 \pm 0.17(n=40$; range, 0.18-0.90) and mean $A B I$ after exercise was $0.33 \pm 0.17(n=34$; range, 0.09-0.77). Based on the criteria mentioned above (rest $A B I$ of $<0.9$ or $>15 \mathrm{~mm} \mathrm{Hg}$ decrease after exercise), 39 patients were diagnosed with PAD. Two additional patients did not fulfill these criteria, but had significantly decreased arterial flow (by ultrasound examination; $\mathrm{n}=$ 1) or significant stenoses (by MRA; $n=1$ ) and were also included. As such, the PAD group included 41 patients.

Patient characteristics. Patient characteristics are provided in the Table. Even though only individuals $\geq 50$ years were selected, patients with CECS were still 15 years younger on average (57 years; range, $50-76$ years) than patients with PAD (72 years; range, 51-93 years; $P<$ .001). The gender distribution and number of patients with bilateral complaints were not different between the groups. Strikingly, diagnostic delay was six times longer in patients with CECS (CECS 36 months vs PAD 6 months; $P<.001$ ). As expected, comorbidities such as hypertension and hypercholesterolemia were more prevalent in the PAD group. No correlation was found between unilateral complaints and a history of leg events in the CECS group. Almost one-half of the patients with CECS (44\% [19/43]) had previously undergone a vascular workup ( $\mathrm{ABI}$, ultrasound examination, MRA) before they were examined by our sports physicians.

Symptoms during rest and exercise. Symptom scores at rest and during exercise are depicted in Fig 2. At rest, patients with CECS reported more pain (4.33 vs 0.59 ; $P<.01$ ), tightness (5.79 vs $0.39 ; P<.01$ ), muscle weakness (1.51 vs $0.30 ; P<.01$ ), and altered sensation (3.21 vs 1.12; $P<$ .01) than patients with PAD. Cramps were comparable in both groups (2.02 vs 1.50; $P=.44$ ). After correction for age, gender, bilaterality, and duration of complaints, having CECS was associated with a higher combined symptom score at rest (difference, 9.9; 95\% confidence interval, 1.818.0; $P=.02$ ).

Exercise increased the combined symptom score in patients with CECS from a median of 14 (range, 0-65) to 29 (range, 11-80). In patients with PAD, the combined symptom score increased from a median of 1 (range, 0-29) to 21 (range, 0-52). During exercise, pain (CECS 10.40 vs PAD 9.44; $P=.36$ ) and cramps (3.33 vs $2.30 ; P=.70$ ) 
Table. Characteristics of patients with exercise-induced lower leg pain owing to chronic exertional compartment syndrome (CECS) or peripheral artery disease (PAD)

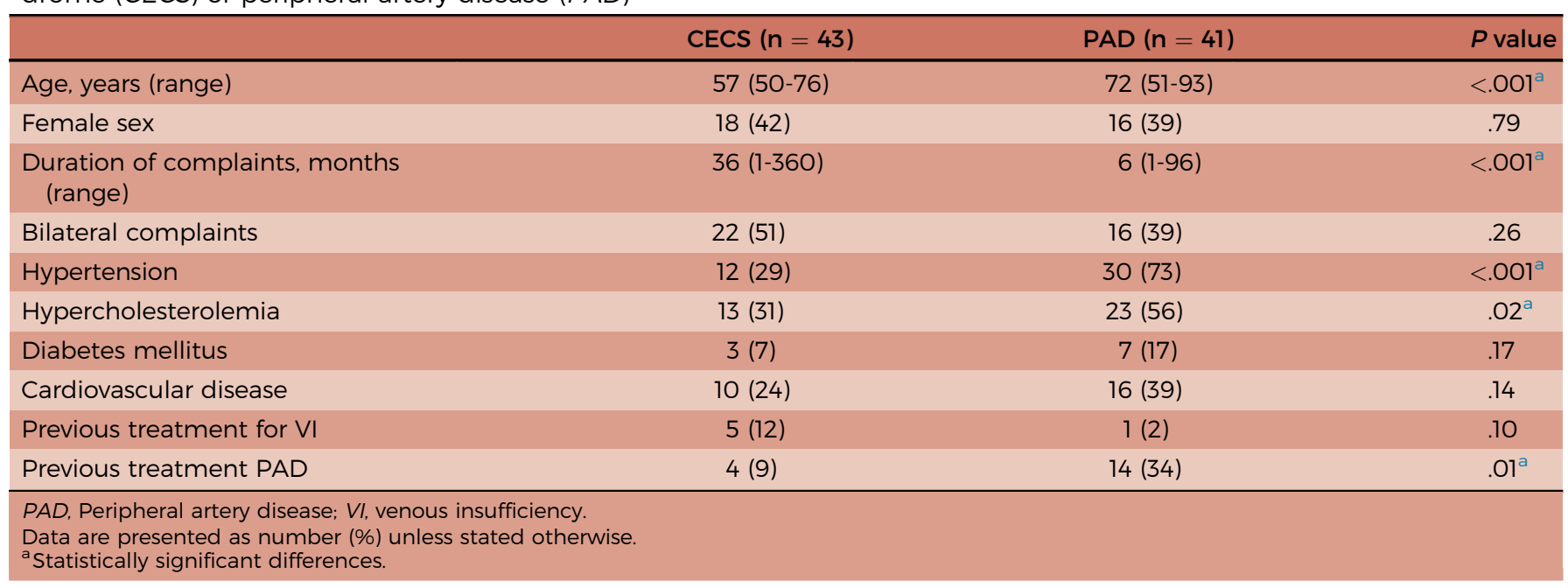

were comparable. However, patients with CECS experienced more tightness (9.19 vs 3.93; $P<.01$ ), muscle weakness (5.02 vs 1.42; $P<.01$ ), and altered sensation (4.74 vs 2.05; $P<.01)$ than patients with $P A D$. After correction for age, gender, bilaterality, and the duration of complaints, having CECS was not associated with a higher combined symptoms score (difference, 6.2; 95\% confidence interval, -2.5 to $15 ; P=.16)$.

Onset of symptoms after starting exercise. After the initiation of exercise, symptoms started 11 minutes earlier in patients with PAD (median, 4 minutes; range, 1-30 minutes) than in patients with CECS (median, 15 minutes; range, 1-240 minutes; $P<.001$, Fig 3). A time of $>4.5$ minutes between the initiation of the provocative activity and the start of complaints proved most discriminative of the presence of CECS based on a receiver operating characteristic curve (sensitivity, 95\%; specificity, 54\%; PPV, 68\%; negative predictive value, 92\%). In the current population, a time of $>4.5$ minutes between the initiation of the activity and the start of complaints meant that the probability of that patient having CECS was 68\%. Conversely, if symptoms started within the first 4.5 minutes, the probability of having CECS was low ( $8 \%$ in this sample).

All patients with PAD $(n=41)$ reported that cessation of the provocative activity completely alleviated lower limb complaints. In contrast, almost threequarters of patients with CECS ( $\mathrm{n}=29$ [73\%]; $P<$ .001) experienced persisting complaints after cessation of the provocative activity. Ongoing discomfort after discontinuation of the provocative exercise was associated with the diagnosis CECS (sensitivity, 73\%; specificity, 100\%; PPV, 100\%).

\section{DISCUSSION}

The diagnostic delay in patients with CECS, irrespective of age, is substantial. We noticed that some older patients with CECS had previously consulted (vascular) surgeons to exclude PAD, but CECS was not considered during these consultations. Some of the symptoms and patient characteristics associated with both entities may overlap. Therefore, the current study aimed to compare the characteristics and symptoms of patients with CECS and patients with PAD. As was expected, patients with PAD hardly experienced discomfort during rest. Most patients with CECS, however, did report discomfort, albeit minor. In addition, PAD mostly caused lower limb pain, whereas CECS often also caused tightness, muscle weakness, and altered sensation. Moreover, symptoms appear and disappear much faster after initiation and discontinuation of a provocative activity in patients with PAD than in patients with CECS.

Patients of advanced age with atherosclerotic risk factors who report walking-induced lower limb pain are most likely to have lower extremity PAD. Plaque formation in PAD is due to aging and the ongoing presence of these risk factors. ${ }^{2,13}$ In contrast, CECS is associated with younger age, and its incidence decreases as age advances. ${ }^{20}$ However, there are some reports that describe the possibility of CECS in older patients with exerciseinduced lower limb pain. ${ }^{16,17}$ In fact, a recent study demonstrated that one in seven patients diagnosed with CECS was $\geq 50$ years of age. ${ }^{18}$ The current study confirms that CECS does affect older individuals up to an age of 76 years. We hypothesize that the diagnosis of CECS later in life is partly caused by underdiagnosis in the previous years, but also by an increased availability of leisure time around the age of 50. 

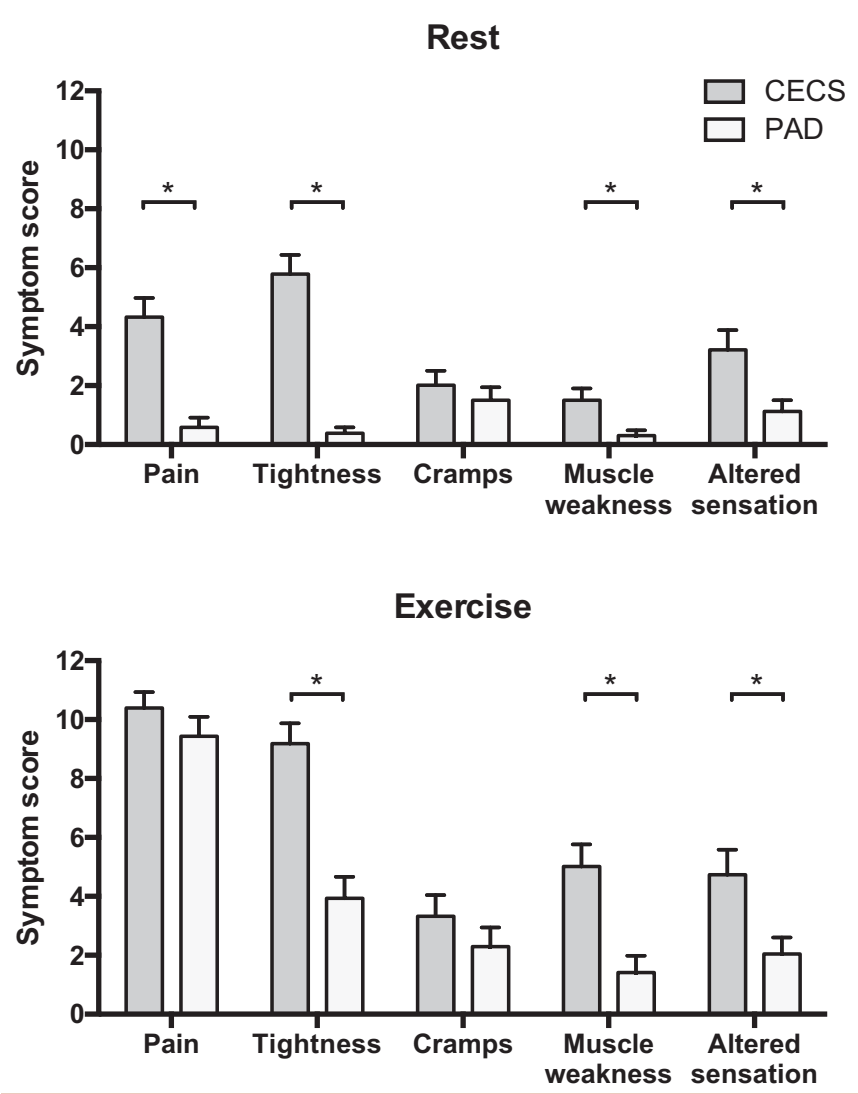

Fig 2. Symptom scores at rest (top) and during exercise (bottom) of patients with chronic exertional compartment syndrome (CECS) or peripheral artery disease (PAD). Scores range from $\mathrm{O}$ to 16 and are comprised of intensity and frequency. Bars represent mean scores and error bars represent standard error of the mean. *Statistically significant differences between the groups.

A number of aspects in the patient history differ considerably between patients with PAD and patients with CECS. Hypertension and hypercholesterolemia play an important role in the pathophysiology of PAD, but have no known correlation with CECS. ${ }^{13}$ Diabetes mellitus, in contrast, is a risk factor for PAD, but is also occasionally seen in patients with CECS. ${ }^{17}$ Our results confirm these beliefs; hypertension and hypercholesterolemia are clearly associated with PAD and rates of diabetes were comparable in both groups. Although PAD often causes the most invalidating complaints in one leg. CECS predominantly ( $\leq 80 \%$ ) affects both legs equally. ${ }^{22,23}$ In older patients with CECS, however, rates of bilaterality are remarkably lower. ${ }^{18}$ The current study confirms that bilaterality is not associated with CECS in patients aged $\geq 50$ years; only one-half of the patients have bilateral complaints. Hypertension and hypercholesterolemia may be indicative of PAD, whereas presence of diabetes and bilaterality do not help in discriminating between CECS and PAD in patients with exercise-induced lower limb pain.

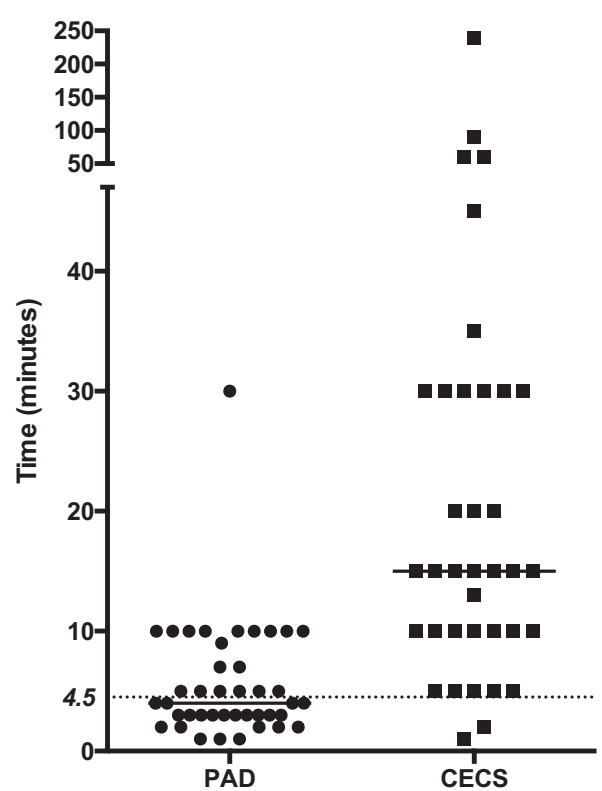

Fig 3. Time between the initiation of the provocative activity and the start of symptoms. The horizontal line represents the median. A time of 4.5 minutes has the highest discriminative capability (sensitivity, 95\%; specificity, 54\%; positive predictive value, 65\%) for detecting chronic exertional compartment syndrome (CECS). PAD. Peripheral artery disease.

Although CECS and PAD both cause exertional pain, a number of distinct differences may help in discriminating between the two. IC is a well-known symptom of PAD and is recognized as a valuable determinant for its detection.' Typically, only advanced PAD causes pain at rest. CECS is also characterized by exercise-induced lower limb pain and tightness. ${ }^{9}$ Additionally, some patients also experience cramps, muscle weakness, and/or altered lower leg skin sensations." Some studies, however, have suggested that these complaints may be less typical in older patients with CECS. ${ }^{16,18}$ In line with the literature, our patients with PAD hardly experienced complaints at rest, but walking quickly induced pain. In contrast, the majority of our older patients with CECS reported some discomfort at rest that worsened significantly during exercise. Furthermore, patients with CECS also experience more tightness, muscle weakness, and altered sensation than patients with PAD. In fact, logistic regression revealed that the presence of CECS was associated with a higher level of complaints at rest.

It is a generally accepted belief that symptoms caused by both CECS and PAD are provoked by physical activity and disappear with rest. In patients with PAD, IC is typically described as progressive calf pain that starts shortly after the initiation of exercise and limits walking capacity. ${ }^{24}$ It usually disappears within 10 minutes after cessation of the provocative activity. In contrast, symptoms characterizing CECS are less well-defined. Typically, its onset is thought to occur at a relatively predictable 
time point after initiation of the provocative activity. ${ }^{9}$ However, this point can vary substantially among individual patients. Pain and tightness in CECS progressively increase during exertion and are reported to improve dramatically within minutes after cessation. ${ }^{10}$ However, a number of studies found prolonged duration of complaints that may even last until the next day. ${ }^{25}$ Our results indicate that complaints arise almost four times faster in patients with PAD than in patients with CECS. Furthermore, whereas complaints quickly disappeared after cessation of the provocative activity in all patients with PAD, almost three-quarters of patients with CECS reported ongoing complaints, albeit at a lower intensity. Therefore, a longer time from the initiation of exercise to the start of complaints as well as ongoing complaints after exercise cessation are indicative of CECS.

The current study has limitations. The main limitation is the questionnaire that was developed for CECS and is not (yet) validated. It was not designed for PAD and may, therefore, miss certain characteristics of the symptom complex of these patients. However, as is shown by the differences in patient-reported outcomes at rest and during exercise, the questionnaire was responsive to changes in the experienced intensity and frequency of symptoms. Furthermore, patients with CECS were analyzed at the department of sports medicine and did not routinely undergo vascular testing with $A B I$ (or ultrasound examination/MRA). Conversely, patients with PAD, who were selected at the department of vascular surgery, did not undergo an ICP measurement. Clinicians routinely checked for physical signs of both entities; none of the patients with CECS had clinical signs of PAD and none of the patients with PAD had clinical signs of CECS. However, because this judgment is solely based on clinical parameters, there is no absolute certainty that not one of the patients suffered from both CECS and PAD. Because both groups were selected from different outpatient departments and were not matched, the introduced selection bias may have resulted in overestimation of the differences found in this study.

In conclusion, this study demonstrates that it is possible to differentiate between PAD and CECS in patients $\geq 50$ years of age with exercise-induced lower limb pain based on symptoms and characteristics. Complaints at rest, the presence of symptoms other than pain, or lingering symptoms after discontinuation of the provocative activity may suggest presence of CECS. These findings may help a vascular surgeon in recognizing CECS in older patients with exercise-induced lower limb pain. We recommend referring these patients to a specialized sports physician once PAD is ruled out.

The authors thank M. van der Cruijsen-Raaijmakers for performing analyses in individuals suspected of having CECS and for collecting questionnaires in these patients.

\section{AUTHOR CONTRIBUTIONS}

Conception and design: JdB, JT, MS

Analysis and interpretation: JdB, KW, SvK

Data collection: JdB, KW, $\mathrm{AH}$

Writing the article: JdB, KW

Critical revision of the article: JdB, KW, SvK, AH, JT, MS

Final approval of the article: JdB, KW, SVK, AH, JT, MS

Statistical analysis: JdB, SvK

Obtained funding: Not applicable

Overall responsibility: JdB

\section{REFERENCES}

1. McDermott MM, Greenland P, Liu K, Guralnik JM, Criqui $\mathrm{MH}$, Dolan NC, et al. Leg symptoms in peripheral arterial disease: associated clinical characteristics and functional impairment. JAMA 2001:286:1599-606.

2. Selvin E. Prevalence of and risk factors for peripheral arterial disease in the United States: results from the National Health and Nutrition Examination Survey, 1999-2000. Circulation 2004;110:738-43.

3. Lane R, Nguyen T, Cuzzilla M, Oomens D, Mohabbat W, Hazelton S. Functional popliteal entrapment syndrome in the sportsperson. Eur J Vasc Endovasc Surg 2012;43:81-7.

4. Schep G, Bender MHM, van de Tempel G, Wijn PFF, de Vries WR, Eikelboom BC. Detection and treatment of claudication due to functional iliac obstruction in top endurance athletes: a prospective study. Lancet 2002;359:466-73.

5. Celecova Z, Krahulec B, Lizicarova D, Gaspar L. Vasculitides as a rare cause of intermittent claudication. Bratisl Lek Listy 2013;114:353-6.

6. Apigian AK, Landry GJ. Basic data underlying decision making in nonatherosclerotic causes of intermittent claudication. Ann Vasc Surg 2015;29:138-53.

7. Ehsan O, Darwish A, Edmundson C, Mills V, Al-Khaffaf H. Non-traumatic lower limb vascular complications in endurance athletes. Review of literature. Eur J Vasc Endovasc Surg 2004;28:1-8.

8. Qvarfordt P, Christenson JT, Eklöf B, Ohlin P. Saltin B. Intramuscular pressure, muscle blood flow, and skeletal muscle metabolism in chronic anterior tibial compartment syndrome. Clin Orthop Relat Res 1983;179:284-90.

9. Blackman PG. A review of chronic exertional compartment syndrome in the lower leg. Med Sci Sports Exerc 2000;32(3 Suppl):S4-10.

10. Brennan FH, Kane SF. Diagnosis, treatment options, and rehabilitation of chronic lower leg exertional compartment syndrome. Curr Sports Med Rep 2003;2:247-50.

11. Fraipont MJ, Adamson GJ. Chronic exertional compartment syndrome. J Am Acad Orthop Surg 2003;11:268-76.

12. Tucker AK. Chronic exertional compartment syndrome of the leg. Curr Rev Musculoskelet Med 2010;3:32-7.

13. Criqui $\mathrm{MH}$, Aboyans V. Epidemiology of peripheral artery disease. Circ Res 2015;116:1509-26.

14. Clanton TO, Solcher BW. Chronic leg pain in the athlete. In: Kwong PK, editor. Foot and ankle injuries. Clinics in Sports Medicine. Philadelphia (PA): W. B. Saunders; 1994. p. 743-59.

15. Waterman BR, Liu J, Newcomb R, Schoenfeld AJ, Orr JD, Belmont PJ. Risk factors for chronic exertional compartment syndrome in a physically active military population. Am J Sports Med 2013:41:2545-9.

16. Edmundsson D, Toolanen G, Sojka P. Chronic compartment syndrome also affects nonathletic subjects: a prospective study of 63 cases with exercise-induced lower leg pain. Acta Orthop 2007;78: 136-42.

17. Edmundsson D, Toolanen G. Chronic exertional compartment syndrome in diabetes mellitus. Diabet Med 2011;28:81-5.

18. de Bruijn JA, van Zantvoort APM, Winkes MB, van der CruijsenRaaijmakers M, Hoogeveen AR, Teijink JAW, et al. Lower leg chronic exertional compartment syndrome in atients 50 years of age and older. Orthop J Sports Med 2018;6. 2325967118757179.

19. Winkes MB, Hoogeveen AR, Houterman S, Giesberts A, Wijn PF, Scheltinga MR. Compartment pressure curves predict surgical outcome in chronic deep posterior compartment syndrome. Am J Sports Med 2012;40:1899-905. 
20. de Bruijn JA, van Zantvoort APM, van Klaveren D, Winkes MB, van der Cruijsen-Raaijmakers M, Hoogeveen AR, et al. Factors predicting lower leg chronic exertional compartment syndrome in a large population. Int J Sports Med 2018;39:58-66.

21. Pedowitz RA, Hargens AR, Mubarak SJ, Gershuni DH. Modified criteria for the objective diagnosis of chronic compartment syndrome of the leg. Am J Sports Med 1990;18:35-40.

22. Davis DE, Raikin S, Garras DN, Vitanzo P, Labrador H, Espandar R Characteristics of patients with chronic exertional compartment syndrome. Foot Ankle Int 2013;34:1349-54.

23. Howard JL, Mohtadi NG, Wiley JP. Evaluation of outcomes in patients following surgical treatment of chronic exertional compartment syndrome in the leg. Clin J Sport Med 2000;10:176-84.
24. Le Faucheur A, Noury-Desvaux B, Mahé G, Sauvaget T, Saumet JL, Leftheriotis G, et al. Variability and short-term determinants of walking capacity in patients with intermittent claudication. J Vasc Surg 2010;51:886-92.

25. Martens MA, Backaert M, Vermaut G, Mulier JC. Chronic leg pain in athletes due to a recurrent compartment syndrome. Am J Sports Med 1984;12:148-51.

Submitted Jun 9, 2020; accepted Nov 1, 2020. 